\title{
Function-topological model of urban space sectoral zoning
}

\author{
Denis Denisov ${ }^{1}$, Tatyana Zhuravleva, ${ }^{2,}$, Mikhail Zhuravlev ${ }^{2}$, and Elena Kabanova ${ }^{1}$ \\ ${ }^{1}$ Samara State Transport University, 443066, 2B Svobody st., Samara, Russia \\ ${ }^{2}$ Samara State Technical University, 443100, 244 Molodogvardeyskaya st., Samara, Russia
}

\begin{abstract}
This study supplements the function-topological model of analysis of city organization and development with a sectoral model of administrative-territorial division. The function-topological model allows revealing unique features of objects of the same profile, located in different space sectors. Besides, significant objects are usually placed in strictly defined sectors. Identification of general principles of spatial arrangement at all levels from geopolitics to the structure of private farmsteads on the cases of various cities, metropolitan areas and architectural ensembles is of great general scientific significance. It deals with the principles described in regional traditions: the Indian Vastu Vidya and the Chinese Feng Shui. The analysis shows that, on an intuitive level, the same principles are implemented in the activities of specialists, designers, who make decisions about the location of industries, residential areas and architectural complexes. Recognition and study of these principles are hindered by the materialistic attitudes of twentieth-century science. The results of the study lead to a radical step in recognizing many spatial elements of the mythological picture of the world as reliable ones.
\end{abstract}

\section{Introduction}

Functional zoning of a city is an integral part of its existence, ensuring its rational functioning. The city area is differentiated by numerous methods of its use and the typology of development. Functional differentiation of the territory is manifested on various scales: from agglomeration to an architectural ensemble. The largest, generalized level of functional zoning is the city division into residential, industrial and landscape-recreational zones. At a smaller scale of differentiation such as a city courtyard or a block we can also observe specialization of separate sites. In both cases, we can see general laws of distribution of functional zones. Modern urban science considers these processes to be affected by the following groups of factors: location of major transport routes; natural landscape; historical background. Despite significant influence of the above mentioned motives, a city turned out to be a system capable of self-organization. We can see that different cities experiencing the influence of various groups of factors in the process of their development have a similar structure of functional zoning. So there is a general pattern of territorial development, implicit at first glance, but having a significant impact on the

*Corresponding author: tbogdanova6@gmail.com 
distribution of urban areas. The authors of this study propose a function-topological model as a general pattern. It is considered to be the most important, previously unaccounted for factor that has an impact on the organization of urban areas.

In traditional cultures, zoning was carried out with the account of the factor of cardinal points. The Chinese Feng-Shui and the Indian Vastu Vidya [1; 2; 3] (see Fig. 1,2) are popular in Southeast Asia. The modern concept of Vastu Vidya, the subject of which is the ideal home arrangement, is presented in the book of K. Shastri and other popular publications. In the monographic study "The origins as a factor in the organization and development of space: genesis, number, topology, probability, classification" (2016), the team of authors D.V. Denisov, M.Yu. Zhuravlev, N.Yu. Medvedeva and others put forward a hypothesis that the factor of cardinal points is also relevant for the functional zoning of urban spaces [4]. This factor is realized in relation to a certain center, but manifests itself in the form of oppositions. The center of the opposition can be the object characterized by a relative voidness (a square, a park, a forest park, a water body ...), or having few buildings [5]. The authors of the function-topological model believe that this model is implemented in the activities of specialists, designers, who decide on the location of industrial buildings, residential areas and architectural ensembles, on an intuitive level.

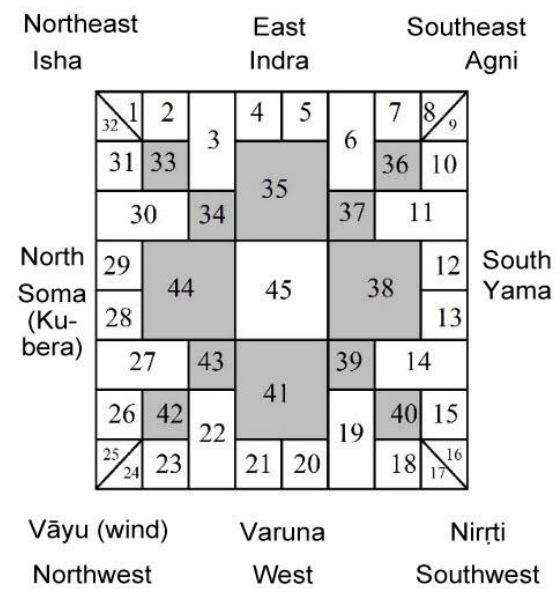

Fig.1. Placement of the East as the sacred cardinal point at the top of the diagram [5, p. 35].

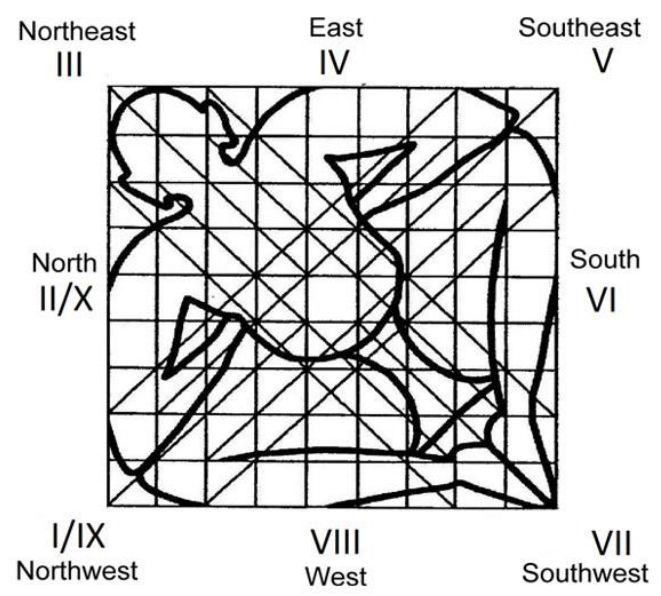

Fig. 2. Orientation of the Purusha-mandala to the Northeast, as the point of impulse detection $[5, \mathrm{p}$. 35] 
The function-topological model is a sectoral model of distribution of functions in the urban space relative to the adopted center, taking into account the illuminating intensity, correlated with the archaic paradigms of various cultures and having a numerical expression. Being a numerical model, the function-topological model includes: goal-setting (el. I, North-West, sector preceding the new daily cycle), eight-element activity cycle (el. II - IX, i.e., from the North to the North-West) and a cognitive tool (el. X, North) (see Fig. 2,3). This solution, which correlates with the numerical model of Sankhya, the ancient Indian philosophy of number, and the Pythagorean numerical model of being [6], features the North-West by two functions: the primary impulse (el. I), on the one hand, and obtaining the result (location of warehouses) and making up the occurring wear and tear (placement of repair plants, hospitals) at the end of the cycle (e-IX), on the other.

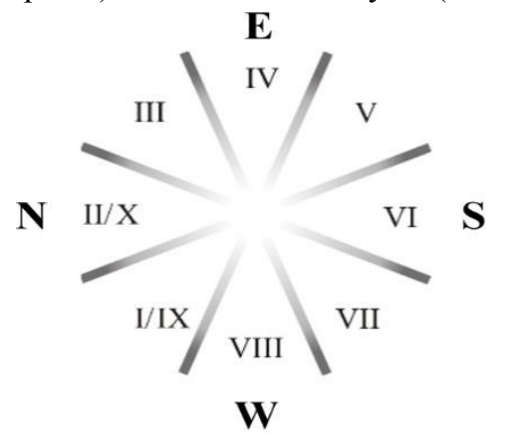

Fig. 3. The relation of Pythagoras first principles and the cardinal points [7, p. 68].

In the function-topological model, the illumination factor is abstracted and symbolized. It acts as a certain condition that creates the prerequisites for a particular type of activity, as in biology, and determines the general trend characterizing the development of a particular sector of space. Thus, lack of activity at night is associated with the lack of light. The symbolic function of the corresponding stage of the daily cycle and the space sector arises as a result of the interpretation of the location of the Sun on the other side of the Earth as a function of potentiality. The numerical model characterizes the northern sector by the sum of two summands: the state of rest and the source of natural potencies (el. II), on the one hand, and the mind/brain power as an instrument of cognition (el. X), mastering these potencies, on the other. This implies the function of placing conservation facilities (museums, tombs, depots, garages, warehouses, large shopping centers, as well as the mint) and the function of placing major authorities for raw materials, transport, and production corporations.

Twilight, i.e., the initial moment of illumination creates prerequisites for such an activity as the perception of an idea (the function of concentration and cognition). Accordingly, a knowing person, perceiving the impulse of a new daily cycle, is introduced in the northeast sector, which is specified in architectural ensembles, for example, in the form of symbolic statues and memorial places (the function of the knowing person). The transition from night to day is interpreted as a transit function. It is reflected in the placement of large transport facilities (el. III) in the northeastern sector.

The light of the morning sun as the light of a new day is the symbol of its main tendencies. It is regarded as the function of determination and choice. Accordingly, the eastern sector includes the "metropolitan" function and the related functions of heroism, entertainment, as well as the function of landscaping (el. IV).

The rising sun is the symbol of dynamic development. In urban planning, the prosperity function is realized symbolically in the southeastern sector as avenues, in commerce - as popular shopping areas and boardwalks, in industry - as industrial complexes with great 
export potential, as well as enterprises producing fuels and lubricants and transport structures (el. V).

The most intensive illumination in the southern sector is the zone in which intense short-term processes are realized. Human life is among them. Therefore, in the Indian mythology, the southern side is the world of mortals and the first mortal, who later became the god of death. Accordingly, in this sector both the function of residential development and the placement of cemeteries are intensively realized. The southern sector houses technological, cultural and managerial facilities that reflect the trend of "everything for the benefit of people" (el. VI). Technological facilities located in this sector require intensive supportive measures.

The next stage is featured by the decrease in intensity. This reflects the tendency to limit some successful and intensive processes, to reorient or reassign them. On the one hand, the South-West is the zone of interventions, on the other, the zone where defense industries are located (i.e., large technological complexes), as well as executive institutions that guarantee the inviolability of the state power (el. VII). The attribute of the Heptad in the Pythagorean tetractys is "the absence of extension: a critical moment, an accident; a strong fortress".

The western side of the world is full of contradictions. On the one hand, the softness of the setting sun indicates elimination of contradictions (el. VIII). On the other hand, at this stage, the results are obtained of both the positive trends (functions of traditional education, demonstration of military prowess) and all the negative trends (for example, in political, financial confrontation). As a result, negative trends prevail as more dynamic. Being strengthened by the totality of positive achievements, they form the prerequisites for an aggressive attitude towards the rest of the world.

Such factors, not taken into account earlier, are integrated into a function-topological model. Within the framework of this study, megalopolises with a sectoral model of administrative-territorial division, not yet represented in the function-topological theory, become the object of the functional analysis.

One of the sources of information about the relationships arising between spatial objects is the research on socio-cultural dynamics. So, the realities of modernity are formed by the technology-oriented North, generating ideas (the northern capitals of Paris and Berlin [8], St. Petersburg and Vologda, the northern capital of Ivan the Terrible [9]), whereas the materialistically oriented South effectively embodies these ideas [10]. Moreover, this opposition also has a linguistic meaning [8]. The well-known opposition of the West to the East is expressed in cases of long-term political primacy: Central Russia - in relation to Siberia, Western Europe - in relation to Russia, Great Britain - in relation to Europe and America - in relation to the Old World. The inverse opposition "East-West" affirms the primacy of the East (Russia) in relation to Europe, which is manifested in a periodic, relatively short-term, non-conquering adjustment of the course of universal history $[4, \mathrm{p}$. 117]. Russia's search for its own spatial and mythological mission and authenticity is seen to this day in the creation of a new metageographic image of Northern Eurasia [9].

Oppositions related to the intercardinal points are usually used as single historical and modern geographical concepts, for example: 1) Lugansk and Donetsk (self-proclaimed republics) in the southeast in relation to Kiev (Ukraine); 2) Samara as a reserve capital during the Great Patriotic War - in relation to Moscow; 3) boyar Moscow - in relation to St. Petersburg; 4) rebel Kurdistan - in relation to Ankara (Turkey); 5) Southeast Asia (India, China, etc.) - in relation to Western Europe. In this opposition, the Southeast is distinctive and independent, fertile, rich in the earth's recourses, self-sufficient (up to self-isolation during some historical periods) [4, p. 144, 215-216]. The North-West, the "up-beat" benchmark, is a powerful military-political center. Accordingly, the spatial definition of "North Atlantic" in the name of NATO should be read as "North-West" [4, p. 144, 218219]. 
According to Vedic architecture of Vastu: Principles of building Your ideal home, reflecting current trends in Vastu Vidya [11], the most important area responsible for the sustainable development of the analyzed object is the Northeast. It proposes the location of places of solitude and prayer, and relatively void objects, such as parking lots (in the northern and eastern sectors). The function of the Northeast is conveyed by the image of the rising sun, symbolizing technological progress (the function of scientific knowledge), spiritual growth, longevity and health. The continent of Africa is presented as a negative sample, in which the corresponding sector is "cut off", and the Japanese islands and Lake Baikal, elongated in a northeastern direction [11, p. 20-22] are presented as positive ones. In the study "The Origins ...", the specifics of the north-eastern sector as a transit, marking the transition from night to day (i.e., from one system to another), was determined by means of two functions: primary in the functional development of a territory (function of the knowing person) and location of transit hubs and large transport and communication centers [4, p. 213-215].

The findings of zoo psychology can illustrate the specifics of the cardinal points. Thus, there is no rational explanation to the fact that foxes succeed in mouse hunting $100 \%$ only when jumping from the southwestern sector [12, p. 136] (see also numerous materials on YouTube). However, this fact was recorded in the Indian Vastu-mandalas, securing the south-western sector of the demon Rāhu, swallowing the sun [1, p. 19, 22]. In geopolitics, this is the zone of negative forces impact, striving to capture, as well as the zone of state power establishment.

Analysis of cultural dynamics was supplemented in the study "The Origins ..." by translating mythological characteristics of the cardinal points on the case of the ancient Indian picture of the world into the language of topological functions relevant for modern processes of space development. The total number of the studied urban and local functions was 48, i.e., 6 for each of the eight sectors of space. In addition, the function- topological model includes 24 ontological and 24 individual functions involved, respectively, in the formation and development of space sectors [4, p. 203-224].

The correlation of the function-topological model with 10-element models opens up a further possibility of its application to the probabilistic analysis of structured systems (premises, city districts - on the case of Samara) without their correlation with spatial orientation [13; 4, p. 227-241, 298-309].

\section{Methods}

The sample consisted of different types of large cities and agglomerations of Eastern Europe. Two of them (Moscow, Minsk) have a sectoral model of administrative-territorial division. St. Petersburg was built according to a clear plan, which hasn't undergone any significant changes. The Samara-Tolyatti agglomeration-conurbation (taking into account all urban formations around the Samara Bend in the middle reaches of the river Volga) is a large anthropogenic body formed around a unique natural object. St. Petersburg and Samara (the reserve capital of the USSR during the Great Patriotic War) have the same location in relation to natural objects: Samara is located in the east-southeast of Samara Bend (1550 $\left.\mathrm{km}^{2}\right)$, and St. Petersburg is in the east-southeast of the Gulf of Finland $\left(29,500 \mathrm{~km}^{2}\right)$.

The degree of development of the selected objects is different. So, Pervomaisky (northeastern) districts of Minsk has the population of 233,241 people (8670 people $/ \mathrm{km}^{2}$ ), whereas the North-Eastern Borough of Moscow - 1,431,976 people (14 055.1 people $/ \mathrm{km}^{2}$ ) which is more than six times bigger. In the case of Samara Bend, the sector development is uneven. As for St. Petersburg, which has lots of symbolic sights, the factor of the number of inhabitants was not taken into account in this study. There are nine districts in Minsk: the south is represented by the Leninsky (south-south-east) and Octyabrsky (south-south-west) 
districts, and there's no central district. The presence of the Central Borough (Okrug) in Moscow opens up the possibility of parallel comparison of data for the sectors of the Central Borough (Okrug) represented by districts and for the boroughs that have received designations by the cardinal points.

The carried out analysis includes comparison of the objects distribution within the sectoral functional zones with the function-topological model and previously analyzed cities. Particular attention is paid to the centers of the objects under consideration. City squares, parks (forest parks) and water bodies can be regarded as centers of the urban landscape. These objects, taken as relatively void spaces, usually have minimum utilitarian structures, so we can judge their structure. The authors of the study proceed from the functional-topological model hypothesis that similar spaces also have a special kind of internal (i.e., hidden) structure, which is significant for the development of territories adjacent to them. This means that the potentials contained in such void spaces are realized in the distribution of the surrounding buildings (from the nearest buildings to tens of kilometers).

\section{Results}

The analysis showed that the generally identical location of St. Petersburg and Samara (see Fig. 4) relative to naturally void objects emphasizes their "metropolitan" function of the eastern sector. A slight shift to the southeast symbolizes prosperity. All the analyzed cases showed the eastern sector to have significant green zones and elite residential areas. In three cases, the east is marked by the function of memorial sites for heroes: Moscow (triumphant Red Gate, Partizanskaya metro station), Minsk (Partizansky district), St. Petersburg (Field of Mars, see Fig. 6).

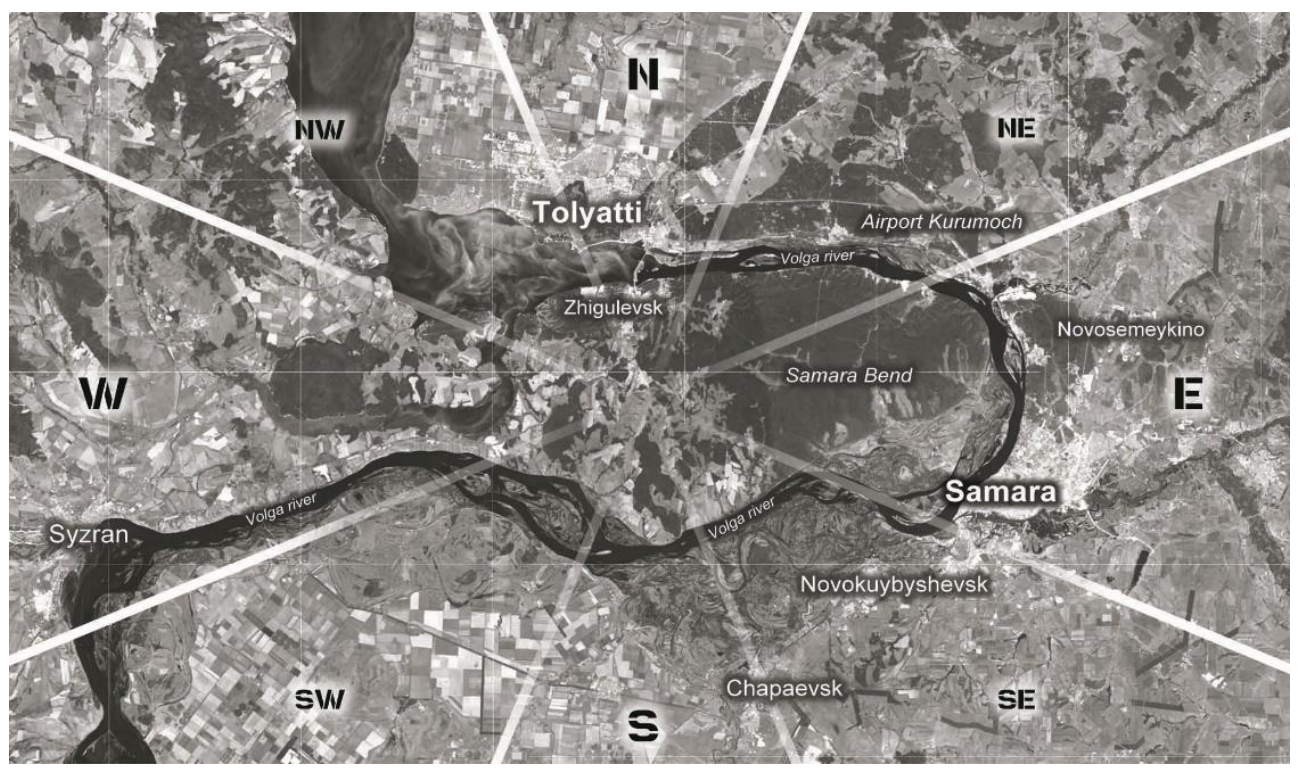

Fig. 4. The sectoral distribution scheme of functional objects, Samara-Tolyatti agglomerationconurbation, original work.

In two cases, the north-east sector is marked by the location of broadcasting centers (Moscow - Ostankino television studio; the village of Novosemeykino - 1942-1943 in the northeast from Samara) and large scientific centers (Minsk - Academy of Sciences; 
Moscow - The Exhibition of Achievements of the National Economy). In three cases, the northeastern sector is marked by the memorial sites that perform the function of the knowing person and primary in functional development: Moscow (sculpture "Worker and Kolkhoz Woman"), St. Petersburg (Cabin of Peter the Great, cruiser Aurora), Minsk (mass grave of victims of fascism and fraternal graves of soldiers of the Soviet Army, partisans and civilians). In two cases, transport facilities of international traffic are located in the northeastern sector (Samara Bend - Kurumoch airport; St. Petersburg - Moscow Railway Station). In Moscow the transport function of this sector is marked by the accumulation of three railway stations - Leningradsky, Yaroslavsky, Kazansky terminals on the Komsomolskaya Square. In two cases, railway terminals are located in the southeastern sectors (St. Petersburg; Samara Bend). In two out of four cases, oil refineries (Moscow; Samara Bend) and automotive enterprises (Moscow; Minsk) are located in the southeastern sector.

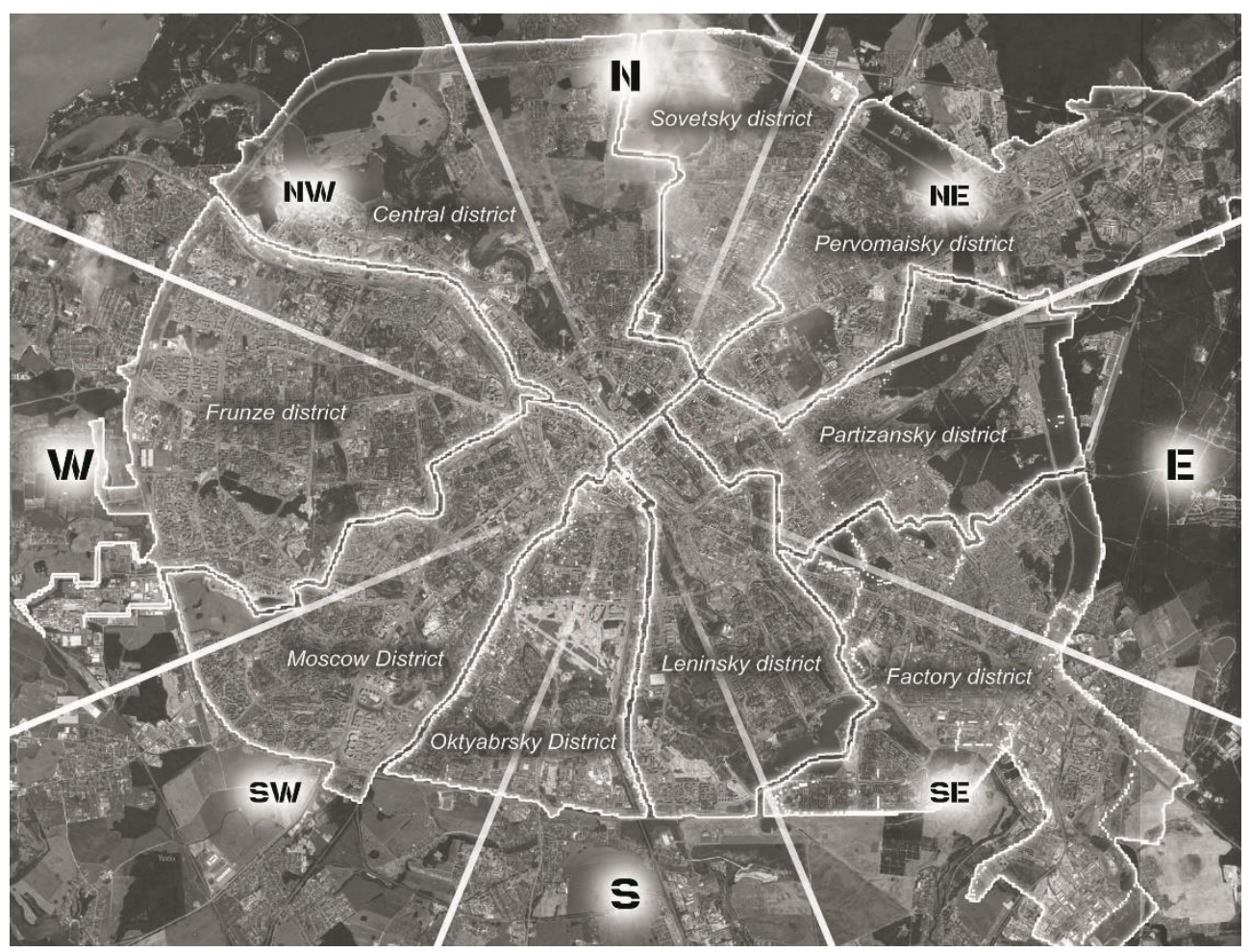

Fig. 5. The sectoral scheme of Minsk administrative-territorial division of, original work.

The following trends are observed in the placement governing bodies. In the northern sector, governing authorities for raw materials, production and transport corporations are likely to be located (Moscow, Minsk). In relation to Samara Bend, such an object is represented by the Zhiguli Hydroelectric Station. In the eastern sector we can see authorities that regulate the course of history, i.e., affect global processes (St. Petersburg, Smolny Institute), including the popular will expression (Minsk, Partizansky, eastern region). The authorities located in the southern sector are focused on the people's wellbeing (St. Petersburg, Minsk). Governing bodies that reflect capitalist tendencies are located in the western sector (Moscow, the building of the Government of the Russian Federation).

Information on the separate cities [14] is given below. 
In Minsk, the starting point is the Central District (see Fig.5), which constitutes the northwestern sector, as in the functional topological model. The Belarus Academy of Sciences is located in the northeast center described above. The special status of the eastern sector is manifested, inter alia, in the function of elite development, and the function of heroism (part of the mythology associated with the East) is reflected in the name of the district (Partizansky district). The southeast is like in Vastu Vidye, a zone of prosperity (Zavodskoy district), namely, the zone for locating export industries, as well as the zone for locating automobile production (in the functional topological model, this is the sector for locating transport hubs). The governing bodies in Minsk are located in the southern sector (the function of power transferred through hierarchical continuity and secular power). This function of the southern sector is represented on the territory of the Leninsky district by the residence of the President of the Republic of Belarus, nine ministries, a number of other government bodies, the Executive Committee of the Commonwealth of Independent States (CIS), as well as eight foreign embassies. The location of the main terminal in Minsk in the southern sector reflects the tendency of the $19^{\text {th }}$ century to place technological facilities for the benefit of the people - in the southern sector.

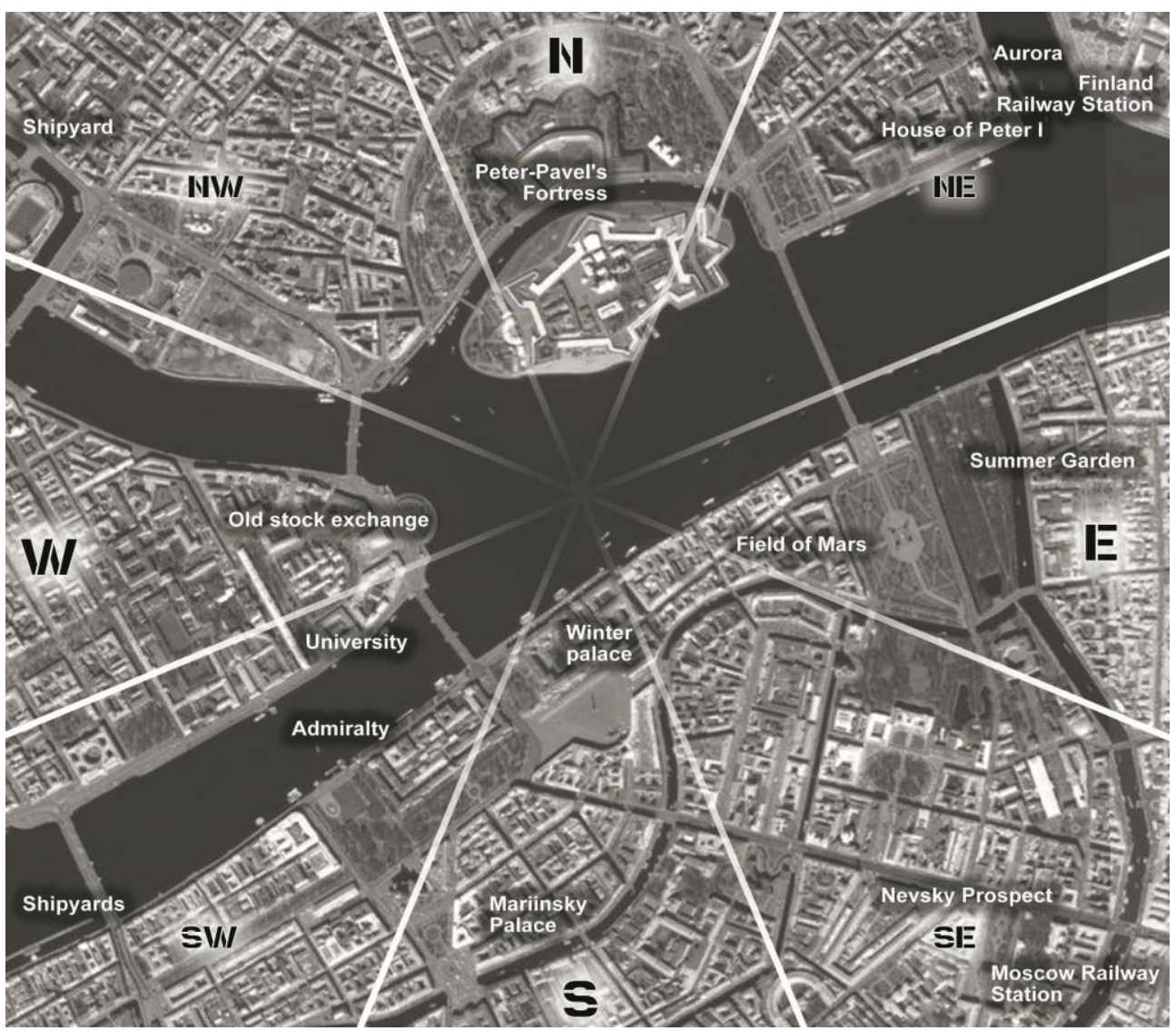

Fig. 6. Sectoral distribution scheme of functional objects in St. Petersburg, original work.

In St. Petersburg, the Neva River between Peter and Paul Fortress, the Hermitage and Vasilyevsky Island was taken as a starting point. The primary in the functional development (also the function of the subject of cognition) is performed by the Cabin of Peter the Great and the famous cruiser Aurora, located in the northeastern sector. In the 
south there is the building of the Legislative Assembly (the function of managing secular authorities). In the east - the Field of Mars (a function of heroism), the Summer Garden (in accordance with the ancient Indian mythology determining that deities live among trees) and the Smolny Institute, which became the Bolshevik headquarters (the function of adjustment of the Western trends in the country's development). In the north there is a rest point (in the form of the Peter and Paul Fortress, which has never been in a fight), which is the source of many potentialities (the function of placing the mint). The function of the international transport facility in the northeast is performed by the Finland Railway Station, and that of the internal transport facility in the southeast - by the Moscow Railway Station. The southeastern sector is known for the famous Nevsky Prospect (prosperity function). The function of the defense facility is represented by the presence of shipyards in the northwestern sector, and the function of correcting damage (deterioration, illness) is represented by the presence of repair plants in the northwestern sector. The function of traditional education is implemented on Vasilievsky Island (western sector) in the location of St. Petersburg State University there.

Moscow requires more attention than the previously described cities. The Northwest Borough (Okrug), i.e., the first one, and the Northern Borough (Okrug) share the northwestern sector (see Fig.7). In the Northern Borough, the function of locating large industrial corporations (in the function-topological model - the function of network corporations) and railway depots is implemented.

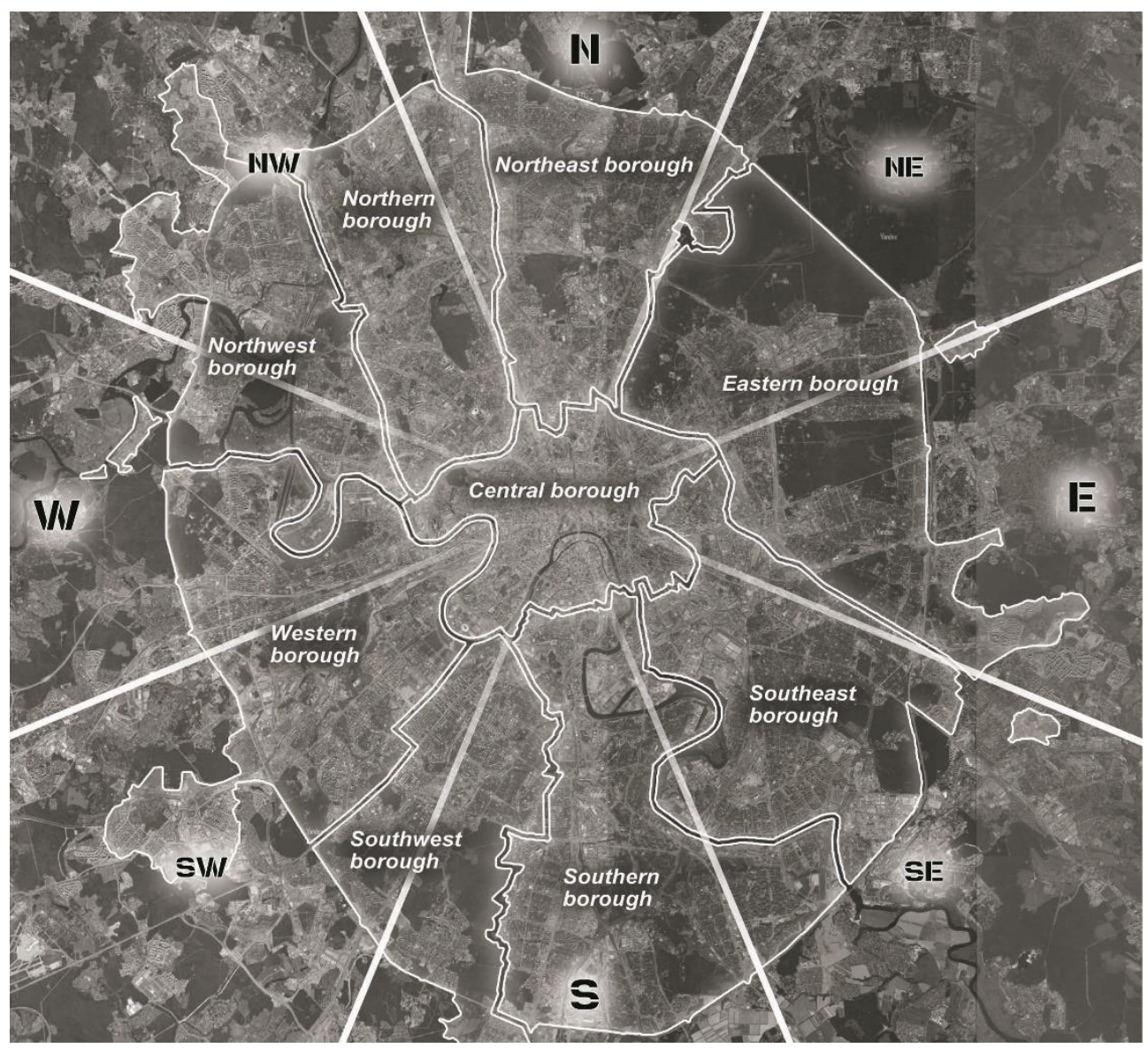

Fig. 7. The sectoral scheme of Moscow administrative-territorial division, original work. 
The Northeast Borough is located in the northern sector of the city. The primary function of this sector can be seen in the fact that the first metro line in Russia (1937) passed through the territory of the Krasnoselsky (northeast) district of the Central Borough. The function of the external transport facility of the North-Eastern Borough in Moscow, filled with railway stations, is implemented in the already mentioned "square of three stations". The function of the northeastern sector as the sector responsible for scientific knowledge is represented by the location in the North-Eastern Borough of the worldfamous Exhibition of Achievement of the National Economy (VDNH), as well as the Ostankino TV tower (the function of placing broadcast centers). The function of the knowing person is symbolized by the sculptural composition of Vera Mukhina "Worker and Kolkhoz Woman" (1937; $24.5 \mathrm{~m}$ tall), located on the roof of the self-titled museum and exhibition center (34.5 $\mathrm{m}$ in hight), which is part of the VDNH complex. The maximum water manifestation expected in Vastu Vidya in the northeastern sector takes on the form of the Rostokinsky aqueduct in Moscow.

The Eastern Borough (Okrug) carrying out the "metropolitan" function incorporated the northeastern sector. There used to be hunting grounds of Moscow sovereigns and grand princely orchards on the territories of both the Baumansky (north-north-east) district of the Central Borough and the Eastern Borough of Moscow. Now there are the Losiny Ostrov National Park, Izmailovsky and Sokolniki Parks, ancient architectural ensembles from the time of Peter the Great - the estates Kuskovo and Izmailovo. The elite function has historically been associated with the German settlement on the Yauza river, which has become the new aristocratic center of Peter's Moscow. In the XVIII century, the triumphal Red Gate (a function of heroism) was erected here in the honor of the victory over the Swedes in the Northern War. The function of heroism and the change in the course of history was manifested in the fact that Peter the Great began to gather his Amusing troops on the territory of the Eastern Borough. These troops later became the prototype of the regular Russian army. Partizanskaya metro station is located in the Eastern Borough, as in Minsk the eastern region is called Partizansky.

The Southeast Borough (Okrug) of Moscow has great industrial potential, as in Minsk. The function of locating facilities for the production of fuels and lubricants is actively being implemented, the transport function - in Soviet times, the Leninsky Komsomol Automobile Plant was located there (See Minsk), now it is the technopolis "Moscow".

In the Southern Borough (Okrug) of Moscow, which ranks first by the number of inhabitants, the function of housing development is maximally realized. The function of hierarchical power is represented by the "State Historical-Architectural Art and Landscape Museum-Reserve "Tsaritsyno"'(100 ha). The function of intensive management includes 186 enterprises and organizations of the scientific and industrial complex, 16.5 thousand small and medium-sized enterprises.

Khamovniki, the southwestern district of the Central Borough (Okrug) of Moscow, located at the turn of the Moskva River, is a concentration area for a large number of museums, including the State Museum of Fine Arts named after A.S. Pushkin. If we count from the north-western sector, which is considered the first in the function-topological model, then the south-western sector becomes the seventh. In the Pythagorean tetraktis seven (Heptad) is the number of Athena Pallas (Warrior). Is it a coincidence that Khamovniki houses the world-famous Novodevichy Convent (also New Maidens' Monastery; founded in 1524) and the Conception Convent (founded in 1584)? The presence in this sector of the reconstructed Cathedral of Christ the Savior and the working residence of the Patriarch of Moscow and All Russia implements the function of locating institutions that support the executive branch (as well as the function of defense facilities), in this case, the spiritual one. 
Arbat is the western region of the Central Borough. On its territory there are important ministries: the Ministry of Defense of Russia (the function of military glory objects), the Ministry of Foreign Affairs of Russia, the Ministry of Economic Development (the function of financial institutions). We also refer to the western sector: the Presnensky district, which accommodates the Government House of the Russian Federation (the function of implementing Western political trends), and the Moscow-City business complexes, the World Trade Center (the function of financial institutions).

The Museum at Fili located in the Western Borough (Okrug) performs the function of demonstrating military prowess. The function of traditional education is represented by Moscow State University and other institutions. The Borough is considered one of the most prestigious for living and one of the most environmentally friendly boroughs of Moscow. In Soviet times, numerous institutes and a university were built in many districts of the Borough and on Vernadsky Prospekt, in particular. So the nearby blocks of flats served as the place of residence for university professors, researchers and students. There are many foreign embassies in the Ramenki area.

\section{Discussion}

Appeal to the factor of the cardinal points in urban planning violates the ban on the use of archaic models in solving modern problems in philosophy and methodology of science. The assumption of the possibility of translating mythological images into the language of topological functions means that there are ancient and modern terminological systems and regular translation in both directions is possible. However, it is believed that mythological knowledge and the mythological picture of the world as a whole belong to the pre-scientific stage of cognition and, unfortunately, cannot claim to be updated in the current world picture. But in this study, it was shown that factors that were formulated in the mythological period still affect the probability (frequency) of the distribution of functions in space. Of course, the location of industries, green areas, transport facilities, governing bodies and research institutes can be carried out and is carried out in any of the sectors. The function-topological model allows revealing unique features of objects of the same profile, placed in different sectors, while significant sights are usually placed in strictly defined ones. The proposed study expands the number of objects subjected to function-topological analysis by involving the administrative-territorial division of the cities of Moscow and Minsk.

Despite the unusual nature of this approach, there are some overlapping points with current trends in modern architecture. So, along with the functional and technicaltechnological aspects, the spatial-compositional aspect that is being developed as part of the methodological direction of architectural ecotopology becomes significant [15]. The categories and concepts that reflect environmental values and types of architectural ecological spaces are decisive for this area. The function-topological approach correlates with the following principles of architectural topology: a) the principle of integrity and unity of man and the environment (aspects of psychophysiological comfort, the organic interaction of man and the environment, formation and character of space), b) the principle of normativity (accounting and coordination of positive and negative, and also aesthetic qualities of the environment); c) the principle of ecocyclicity, i.e., the coordination of the rhythms of the environment and humans; d) the principle of phenomenology (taking into account the specific situation of place-time, social conditions, characteristics of an individual and ethnoculture as a whole) [6]. The authors of the study "The Origins ..." add to these four principles the principle of constancy, going back to mathematical topology, which studies the properties of figures (spaces) that are preserved under continuous deformations. It is a stable character that can facilitate its intuitive perception. It forms the 
basis for the future rational development of the object with the account of all significant factors.

\section{Conclusions}

According to the results of the analysis conducted on the example of the cities of Moscow and Minsk, it was concluded that in the case of cities with a sectoral model of administrative-territorial division, there are elements of functional zoning, due to the factor of cardinal points. The above comparison with the previously analyzed functional distribution of objects in St. Petersburg and on the territory of the Samara-Togliatti agglomeration-conurbation (taking into account all the cities along the perimeter of Samara Bend) revealed the commonality with the characteristics of functional zones in the function-topological model. The obtained results indicate the promising character of research aimed at a rational explanation of archaic ideas about the properties of space.

\section{References}

1. E.V. Tyulina, The temple, the World, the Text: Vaastuvidyaa in the Tradition of the Puraanas (East literature Press, Moscow, 2010)

2. N. G. Nesterenko, History of world culture: traditions, innovations, contacts, 13-23 (1990)

3. S. M. Neopolitanskij, S. A. Matveev, Sacred architecture of the world. Creative principles of world harmony (Amrita Press, Moscow, 2013)

4. Ed. D. V. Denisov, Origins as a factor in the organization and development of space: genesis, number, topology, probability, classification (Samara: SamGUPS Press, 2016)

5. D.V. Denisov, M. Yu. Zhuravlev, N. Yu. Medvedeva, Postgraduate Bulletin of the Volga Region 7-8, 34-40 (2015)

6. D.V. Denisov, Numbers and Ontological Modeling: towards the method of Sankhya (SSTU Press, Samara) (2013)

7. D. V. Denisov, M. Yu. Zhuravlev, N. Yu. Medvedeva, A. S. Khokhrin, Urban planning and architecture 4, 67-73 (2018)

8. T. Ju. Zagrjazkina, Philosophical sciences 4, 9-28 (2012)

9. V. I. Spiridonova, Philosophical sciences 8, 19-30 (2012)

10. A. A. Lyusy, Philosophical sciences 10, 75-85 (2008)

11. K. Shastri, Vedic architecture of Vastu: Principles of building our ideal home (2014)

12. J. Broschart, Der gepolte Fuchs. GEO 3,136 (2011)

13. N. M. Latypova, D.V. Denisov, XIIth International scientific-practical conference, 78-83 (2016).

14. D.V. Denisov, Urban culture and a city in culture. Materials of the scientific-practical conference in 3 parts 1, 172-189 (2012)

15. V. I. Iovlev, Academic Bulletin Ural NII project of the Russian Academy of Architecture and Construction Sciences 2, 62-64 (2011) 